ARTÍCULO DE REVISIÓN

\title{
Inflamación sistémica y desregulación inmune: rol en la patogénesis de la coinfección VIH/VHC
}

\author{
Recibido: 2/1/20 Aceptado: 13/10/20
}

Alejandra Urioste ${ }^{1}$, María Laura Polo ${ }^{1}$, César Trifone ${ }^{1}$, Gabriela Turk $^{1}$ y Natalia Laufer ${ }^{1}$.

\section{RESUMEN}

La disfunción inmune asociada a la infección por el virus de la inmunodeficiencia humana $(\mathrm{VIH})$ es generada por una estimulación crónica del sistema inmune secundaria a la imposibilidad del organismo de erradicar el virus. La misma se encuentra exacerbada en el contexto de la coinfección por el virus de la hepatitis $\mathrm{C}(\mathrm{VHC})$. La inflamación sistémica producto de la coinfección por ambos virus genera un aumento de la morbilidad y mortalidad en los individuos afectados. Son varios los mediadores solubles de activación inmunológica, como IP-10, TNF-a, IL-6, IL-1 $\beta$ (marcadores de inflamación sistémica); IL-17 (linfocitos T CD4+ Th17); IL-2, IFN-y (linfocitos T CD4+ Th1); IL-8 (inducción de neutrofilia); CD23s, ICAMs, CD14s, CD163s (marcadores de activación de monocitos/macrófagos), niveles circulantes de lipopolisacárido (LPS) (translocación bacteriana); entre otros. Actualmente se necesitan más estudios para lograr definir cuáles serían los biomarcadores de progresión óptimos para el seguimiento de los individuos coinfectados por VIH/VHC.

El objetivo de esta revisión es realizar una reseña sobre los mecanismos inmunopatológicos de la infección por VIH/VHC involucrados en la inflamación, daño hepático y su impacto en la morbimortalidad de los individuos coinfectados.

Palabras clave: VIH, VHC, disfunción inmune, desregulación inmune, inflamación sistémica, inflamación.
${ }^{1}$ Instituto de Investigaciones Biomédicas en Retrovirus y SIDA (INBIRS).

Dirección para la correspondencia: Alejandra Urioste. Instituto de Investigaciones Biomédicas en Retrovirus y SIDA (INBIRS), Facultad de Medicina-UBA, Paraguay 2155 piso 11, Código Postal: C1121ABG, Buenos Aires Argentina. Tel: (+5411) 4508-3689.

Email: aurioste@fmed.uba.ar

Los autores no presentan conflicto de intereses. 


\section{Introducción}

La inflamación sistémica asociada a las infecciones por el virus de la inmunodeficiencia humana $(\mathrm{VIH})$ y el virus de hepatitis $\mathrm{C}(\mathrm{VHC})$ tiene un rol fundamental en la morbimortalidad de los individuos infectados, tomando relevancia en los sistemas de salud globales. La infección por VIH está asociada a una marcada desregulación inmune. En el contexto de la coinfección por VIH/VHC, la misma se profundiza, llevando a un control ineficaz de la infección por VHC. Frente a este panorama, existe un mayor riesgo de progresión acelerada de la enfermedad hepática, desarrollo de carcinoma hepatocelular o incluso necesidad de un trasplante hepático (1). El objetivo de esta revisión es realizar una reseña sobre los mecanismos inmunopatológicos de la infección por VIH/VHC involucrados en la inflamación, daño hepático y su impacto en la morbimortalidad de los individuos coinfectados.

\section{Epidemiología}

Para el año 2016 se reportaron aproximadamente 2,5 millones de personas coinfectadas con VIH/VHC a nivel mundial (2). En Argentina, se estima una prevalencia de infección por VHC que varía entre un $12 \%$ y $60 \%$ en personas infectadas con $\mathrm{VIH}$ (1). Al igual que en el resto del mundo, la prevalencia aumenta a más de un $80 \%$ en aquellas personas infectadas con $\mathrm{VIH}$ usuarias de drogas intravenosas $(1,2)$. De acuerdo a lo reportado en el 1er Boletín de Hepatitis Virales de Argentina (3), el 34\% de los individuos que recibieron tratamiento para la infección por el VHC ( $n=4354)$ entre 2016 y 2019 presentó coinfección por el VIH. Estas cifras se deben a que ambos virus comparten las vías de transmisión: sexual, parenteral y perinatal.

Paradigma del tratamiento en pacientes coinfectados por VIH/VHC

La Organización Mundial de la Salud (OMS) propone la meta de eliminación de la infección por VHC para el año $2030(4,5)$. En este escenario, los individuos coinfectados por VIH/VHC son considerados una población de interés y prioritaria. Esta meta puede plantearse gracias al advenimiento de los antivirales de acción directa (AAD), cuya comprobada eficacia y seguridad permiten lograr una respuesta virológica sostenida, que es sinónimo de eliminación de la infección por $\operatorname{VHC}(2,4,6)$.

\section{Inflamación sistémica y desregulación inmune}

La disfunción inmune asociada a la infección por VIH es generada por una estimulación crónica del sistema inmune secundaria a la imposibilidad del organismo de erradicar el virus. A nivel de las alteraciones de la inmunidad celular, se destacan la disminución de la relación de linfocitos T (LT) CD4+/CD8+ y las respuestas antivirales defectuosas por parte de los linfocitos T CD8+ citotóxicos (7). Este último punto no puede resolverse incluso en aquellos individuos con buena adherencia al tratamiento antirretroviral (TARV), con cargas virales indetectables y valores de linfocitos T CD4+ mayores a 500 células/ $\mu \mathrm{l}$, si bien aquellos individuos que inician el TARV tempranamente, cerca del momento de la infección aguda, pueden verse menos afectados (8).

\section{Respuesta inmune frente a la infección por VIH y VHC}

La inflamación sistémica generada por la infección por VIH comienza, por un lado, con el reconocimiento del ARN viral por los receptores de reconocimiento de patrones, receptores tipo Toll (Toll like-receptors, TLR) fundamentalmente TLR-8, expresados en las células dendríticas plasmocitoides. Este reconocimiento desencadena la activación de las mismas y la producción de interferones tipo I (IFN a/ $\beta$ ). Estos últimos inducen la expresión de genes estimulados por interferón (ISGs, IFN-stimulated genes) tanto en células infectadas como no infectadas, promoviendo un estado antiviral generalizado. La respuesta antiviral incluye la diferenciación de LT CD4+ hacia un perfil Th1, la estimulación del desarrollo de LT CD8+ de memoria a largo plazo, y la estimulación de las células natural killer (NK). Los monocitos, macrófagos y células dendríticas convencionales contribuyen con la inmunomodulación gracias a la producción de citoquinas proinflamatorias, entre otros mecanismos (9). VIH y VHC inducen la producción de especies reactivas del oxígeno, que activan la vía de proteínas quinasas activadas por mitógenos, o MAPK, que regulan la producción de TGF- $\beta$, modulando la respuesta inmune, favoreciendo la fibrosis y la posible transformación hacia carcinoma hepatocelular. En relación a esto, el VIH contribuye a estimular la replicación del VHC en hepatocitos, si bien los mecanismos involucrados no están completamente dilucidados. A nivel hepático, los hepatocitos expuestos al VHC y VIH sufren apoptosis, en particular, por la estimulación de las proteínas E2 del VHC y gp120 del VIH, que inducen dicho mecanismo a través de la vía dependiente de Fas-FasL. Las proteínas del VHC, core y NS3A, a través del TLR-2 y la vía de las quinasas asociadas al receptor de IL-1, conocido como IRAK, desencadenan la estimulación para 
la liberación de citoquinas y quimiocinas inflamatorias por células estrelladas hepáticas (10).

\section{Marcadores solubles de activación inmune en la} patogénesis de la coinfección por VIH/VHC

En el contexto de la coinfección por VIH/VHC, ambos virus interactúan entre sí ejerciendo una variedad de efectos a nivel de la inmunidad innata y adquirida. Además de la profunda desregulación del sistema inmune que se intensifica durante la coinfección por VIH/VHC, existen otras hipótesis que explicarían la contribución de ambas infecciones a la progresión acelerada de la patología hepática. Por un lado, la acción cruzada entre las proteínas del VIH y el VHC modularían la activación del sistema inmune vía mediadores fibrogénicos/ inflamatorios (Figura 1), sumado a la estimulación recíproca de la replicación de ambos virus. Por otro lado, se conoce que el VHC es capaz de estimular la activación de los LT CD4+, favoreciendo la apoptosis de los mismos, contribuyendo a la depleción de este tipo celular en la coinfección por VIH $(10,11)$. La apoptosis de LT CD4+, dando por resultado un desbalance en la relación CD4+/CD8+, correlaciona con una modificación del entorno inmunológico debido a alteración del perfil de citoquinas que desfavorece la respuesta inmune protectora (por ej.: aumento de TGF- $\beta$ y disminución de IFN- $Y$ ) $(12,13)$. Siguiendo esta línea, cabe mencionar el denominado "efecto by-stander", donde los LT CD8+ específicos para VIH en circulación son atraídos al hígado, contribuyendo a la liberación de citoquinas que favorecen un microambiente profibrótico/ proinflamatorio (14).

\section{Figura 1. Marcadores solubles involucrados en la desregulación inmune en el contexto de la} coinfección por VIH/VHC

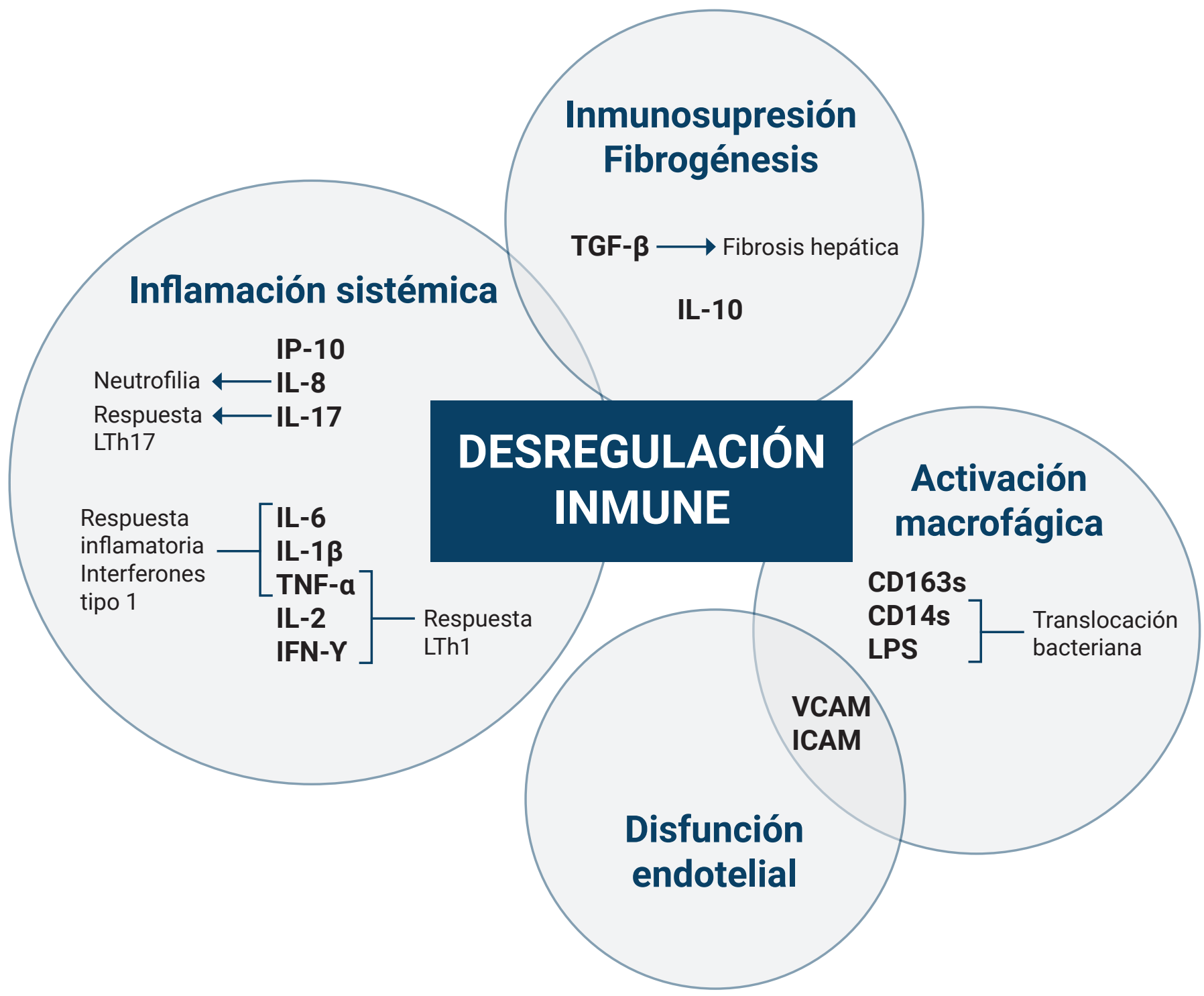


En las infecciones virales se estimula la activación de los macrófagos tanto por la acción directa del virus como por los productos celulares derivados del daño al tejido infectado. Mascia y col. (15) evaluaron la posible relación entre las distintas subpoblaciones de monocitos y los marcadores de activación de monocitos/macrófagos. Realizaron los estudios en base a muestras de sangre periférica en tres grupos de individuos: monoinfectados por $\mathrm{VIH}$, monoinfectados por VHC (con replicación viral activa), y coinfectados por $\mathrm{VIH} /$ VHC. Observaron mayores niveles de monocitos intermedios (CD14+/CD16+) en pacientes monoinfectados por VHC respecto a los monoinfectados por $\mathrm{VIH}$. Teniendo en cuenta a los individuos que no presentaban fibrosis hepática, los valores de monocitos no clásicos (CD14bajo/CD16+) fueron superiores en los individuos monoinfectados por $\mathrm{VHC}$ que en los coinfectados por VIH/VHC. Como marcadores de activación de monocitos/macrófagos evaluaron los niveles en plasma de la porción soluble del receptor del complejo haptoglobina/hemoglobina (CD163s) (15). Observaron una correlación inversa entre CD163s y monocitos clásicos (CD14+/CD16-) en los pacientes monoinfectados por VHC, mientras que, en pacientes coinfectados, la correlación negativa fue con la subpoblación de monocitos no clásicos. Estos resultados sugieren un origen hepático para este marcador, probablemente producido por las células de Kupffer (16).

La porción soluble de la molécula asociada al TLR-4, CD14s no es solo un marcador de activación de monocitos/macrófagos sino también un marcador indirecto de translocación microbiana (favorece la captación de lipopolisacáridos, LPS) (17). La activación crónica del sistema inmune en individuos infectados con VIH estaría relacionada con una desregulación de la mucosa intestinal favoreciendo la translocación de antígenos microbianos. La translocación bacteriana es un factor clave en la patogénesis de la infección por VIH y VHC, especialmente en las etapas avanzadas de la enfermedad, en aquellos individuos que no reciben un tratamiento efectivo. Dada la estimulación crónica provocada por el $\mathrm{VIH}$, la integridad de la mucosa intestinal se ve comprometida, ya sea por depleción o la senescencia inmunológica de los linfocitos T CD4+ en el tejido linfoide asociado al intestino (GALT). Esto trae como consecuencia una mayor permeabilidad intestinal, lo que a su vez crea un microambiente propicio para la translocación bacteriana. En la infección por VHC se observa un fenómeno similar, si bien el mecanismo es diferente. Debido a la cirrosis hepática, se promueven cambios en la microbiota intestinal, lo que desencadena una desregulación de la respuesta inmune en el GALT y por lo tanto un aumento en la permeabilidad. Durante este proceso, las células del sistema inmune son estimuladas por patrones moleculares asociados a patógenos bacterianos, como el LPS, que se une al complejo CD14 / TLR-4 activando la vía del factor nuclear NFk-B e induciendo la síntesis de citoquinas proinflamatorias como el factor de necrosis tumoral a (TNF- a), IL-1 e IL-6, lo cual desencadena la sobreexpresión de otros marcadores de activación crónica (18). La cirrosis está relacionada con una desregulación en el equilibrio entre la activación y la homeostasis del sistema inmune. IP-10 (proteína-10 inducible por IFN- $\gamma$ ) es una quimiocina, producida por varias células, entre ellas los hepatocitos. Esta proteína media el reclutamiento de linfocitos T CD4+, NK y monocitos al sitio de infección (19). IP-10 se asocia a la inflamación hepática, tanto por la transcripción de IP-10 en hepatocitos como por la expresión del receptor de IP-10, CXCR3, en los linfocitos que infiltran el hígado, en individuos con infección crónica por VHC (20).

Medrano y col. (21) evaluaron la relación entre la medición de rigidez hepática, translocación bacteriana (CD14s), marcadores de inflamación (IL-1ß, IL-6, IL-8, IL-18, IP-10) y activación de linfocitos $\mathrm{T}$, como así también de disfunción endotelial (VCAMs, ICAMs y TNFR-1s), en el contexto de la infección por VIH y VHC. Observaron que aquellos individuos coinfectados por VIH/VHC tenían niveles más altos de todos los marcadores mencionados, al compararlos con individuos monoinfectados por VIH e individuos sin patología inmune. Además, encontraron una relación directa entre los valores de medición de la rigidez (elasticidad) hepática y los valores de marcadores de activación (CD38) en linfocitos T CD8+, CD14s, los marcadores de inflamación IL-8, IP-10 y de disfunción endotelial VCAMs, ICAMs y TNFR-1s. Los individuos con cirrosis, cuyos valores de rigidez hepática medidos por elastografía fueron superiores a $40 \mathrm{kPa}$, mostraron valores de marcadores más altos que los individuos con estadios menores de fibrosis.

El trabajo de Shmagel y col. (22) arroja datos similares respecto a algunos marcadores de inflamación. Al comparar los niveles plasmáticos de IL-6, IP-10, CD163s, entre otros, encontraron un aumento significativo en individuos coinfectados por $\mathrm{VIH} / \mathrm{VHC}$ respecto a individuos monoinfectados por $\mathrm{VIH}$. Además, los niveles de CD163s e IP-10 correlacionaron con los valores de transaminasas y el score APRI, pero solo CD163s correlacionó con los niveles plasmáticos de VHC. En basea estos resultados sostuvieron que, aunque no puede excluirse una posible contribución de la hepatotoxicidad inducida por el TARV, los efectos observados están relacionados con el daño hepático inducido por VHC. Siguiendo con CD163s, pudieron evidenciar una correlación inversa entre este mediador y el número de 
linfocitos TCD4+ vírgenes recién emigrados del timo (CD31+). Si bien la relación entre estos índices no es clara, es posible que los procesos que tienen lugar en el hígado puedan desempeñar un papel relevante en la recuperación de los linfocitos T CD4+ durante el TARV en el contexto de la coinfección por VIH/VHC. Al medir LPS, encontraron mayores niveles plasmáticos en individuos coinfectados por $\mathrm{VIH} / \mathrm{VHC}$ que en monoinfectados por VIH. Curiosamente, al momento de evaluar los valores de CD14s, los resultados fueron comparables en ambos grupos de individuos, a diferencia de lo mencionado anteriormente por el grupo de Medrano y col. (21). La alteración en la eliminación hepática de LPS secundario a la infección por VHC podría explicar los mayores niveles de LPS en sangre periférica en los individuos coinfectados respecto a los monoinfectados por VIH. Por último, no encontraron una relación entre CD14s y los índices de daño hepático.

En un estudio (23) realizado sobre una cohorte de 79 mujeres serológicamente reactivas para VHC (37 presentaban ARN $\mathrm{VHC}<50 \mathrm{UI} / \mathrm{ml}$ ), los autores sostenían la hipótesis que encontrarían respuestas inflamatorias disminuidas y un menor grado de fibrosis hepática en mujeres que controlaban la replicación de VIH respecto a las que no lo hacían. Se incluyeron los siguientes grupos: controladores Elite (CE: sin TARV previo, LT CD4+ > 500 células/ml, carga viral (CV) $\mathrm{VIH}<80$ copias/ml); mujeres bajo TARV con infección VIH controlada (TARVC: LT CD4+ > 350 células $/ \mathrm{ml}, \mathrm{CV}$ VIH $<80$ copias/ml) y no controlada (TARVnc: $\mathrm{CV}$ VIH $\geq 80$ copias $/ \mathrm{ml}$ ). Se utilizó un grupo control de mujeres no infectadas con VIH. En los grupos CE y TARVc se observaron menores niveles de IP-10 respecto al grupo TARVnc. Encontraron una asociación entre la fibrosis hepática y los marcadores IP-10, IL-10, VCAMS, ICAMs. En las mujeres con ARN VHC detectable, las puntuaciones del score APRI se elevaron, como así también los niveles de VCAMs, ICAMs e IP-10. El score APRI en estas mujeres se correlacionó positivamente con los marcadores de inflamación y se observaron concentraciones más altas de estos marcadores especialmente en el grupo TARVnc. La inflamación sistémica exacerbada en la coinfección VIH/ VHC fue evidenciada también por la presencia de niveles más elevados de TNF-a en el grupo TARVnc.

Uno de los tantos mecanismos de acción de los linfocitos T regulatorios (LT reg) es la secreción de IL-10 y TGF- $\beta$. La primera inhibe la síntesis de citoquinas proinflamatorias, mientras que la segunda tiene un efecto tanto inmunosupresor como profibrótico. TGF- $\beta$ promueve la activación de las células hepáticas estrelladas, la acumulación de componentes fibrilares, y la progresión a fibrosis y cirrosis, con el posible desarrollo de hepatocarcinoma. García-Broncano y col.
(24) reportaron que individuos coinfectados por $\mathrm{VIH} / \mathrm{VHC}$ presentaban mayores niveles de LT reg e IL-10, pero no de TGF- $\beta$, que individuos monoinfectados por VIH y controles no infectados. Por otro lado, en el grupo de individuos coinfectados con $\mathrm{VIH} / \mathrm{VHC}$ observaron que mayores niveles de rigidez hepática (determinados por elastografía) estaban asociados con menores valores de IL-10 (LT regs), IL-2, TNF-a (LT th1) e IL17A (LT th17). Excepto para IL-10, esta disminución era mucho más acentuada en individuos con fibrosis hepática avanzada, convalores de rigidez $\geq 25 \mathrm{KPa}$. Los autores sostenían que estos resultados podrían atribuirse a la disfunción inmune propia del proceso fibrótico hepático, que a su vez está favorecida por la translocación bacteriana y el agotamiento del sistema inmune debido a la activación crónica que esta produce, además de la presencia de VIH. Los niveles de IL-2 suelen descender tanto en la infección por VIH como en la infección por VHC crónica, y estarían asociados a mal pronóstico en ambas infecciones (25). Además, TNF-a jugaría un rol importante en la progresión a inmunodeficiencia en el contexto de VIH y en el desarrollo de cirrosis (26), mientras que menores niveles de IL-17A pueden atribuirse a la destrucción de los linfocitos T CD4+ Th17 (27).

Previo al inicio del tratamiento con AAD, niveles elevados de CD163s se asociaban a mayores grados de fibrosis hepática en pacientes coinfectados por $\mathrm{VIH} / \mathrm{VHC}$, mientras que no se evidenció dicha asociación con los de niveles CD14s. Una disminución de los niveles plasmáticos tanto de CD163s como de CD14s luego de 24 semanas post tratamiento con $\mathrm{AAD}$ en individuos coinfectados con $\mathrm{VIH} / \mathrm{VHC}$ sugiere que la eliminación de la presencia de VHC tendría un efecto beneficioso en la reducción de la activación inmune. Esto fue observado en grupos de individuos que lograron una respuesta virológica sostenida, ya sea con viremia $\mathrm{VIH}$ indetectable $(<40$ copias/ml) o con una CV baja que no superaba las 100 copias/ $\mathrm{ml}$ (28). La reducción de CD14s y CD163s luego del tratamiento con AAD también fue reportada en individuos monoinfectados por VHC $(29,30)$. En individuos monoinfectados por $\mathrm{VIH}$, niveles elevados de ambos marcadores se asociaron de forma independiente con un mayor riesgo de mortalidad $(31,32)$. Toda esta evidencia sugiriere que la reducción en la activación inmune puede jugar un papel en la disminución del riesgo de morbimortalidad en individuos coinfectados con $\mathrm{VIH} / \mathrm{VHC}$ que responden a la terapia con AAD.

Nuestro grupo se encuentra realizando estudios relacionados con esta temática y se ha centrado en evaluar los niveles plasmáticos de mediadores solubles de inflamación y/o inmunomodulación en individuos coinfectados por $\mathrm{VIH} / \mathrm{VHC}$ antes y después de iniciado el tratamiento para VHC con AAD (ver Tabla 1). También se estudiaron los reservorios de VIH 


Tabla 1. Valores de los marcadores solubles analizados en las distintas etapas del tratamiento con
ADD
\begin{tabular}{|c|c|c|c|c|c|c|}
\hline Marcador & Etapa Tratamiento HCV & $\mathrm{p}(1-2)$ & $\mathrm{p}(\mathbf{2 - 3})$ & $\mathrm{p}(1-3)$ \\
& Basal (1) & Final $(\mathbf{2})$ & $\mathbf{1 2}$ meses post tratamiento $(3)$ & & & \\
\hline IP-10 (pg/ml) & $1534(410,0 ; 2067)$ & $290,9(165,3 ; 355,6)$ & $363,7(141,1 ; 605,9)$ & $<0,0001$ & 0,0580 & 0,0107 \\
\hline CD23s (pg/ml) & $122,2(78,30 ; 154,0)$ & $118,1(81,95 ; 158,6)$ & $131,5(66,40 ; 189,9)$ & 0,3289 & 0,2163 & 0,0479 \\
\hline ICAMs (ng/ml) & $1491(1047 ; 1868)$ & $118,1(81,95 ; 158,6)$ & $825(536 ; 1012)$ & $<0,0001$ & 0,7148 & 0,0001 \\
\hline IL-6 (pg/ml) & $6,3(2,4 ; 10,9)$ & $2,4(2,4 ; 8,4)$ & $2,4(2,4 ; 8,5)$ & 0,6875 & 0,3125 & 0,2188 \\
\hline IL-8 (pg/ml) & $8,8(5,2 ; 12,8)$ & $4,2(1,6 ; 7,0)$ & $5,6(1,6 ; 8,8)$ & 0,0015 & 0,5633 & 0,0468 \\
\hline IL-2 (pg/ml) & $3,9(3,9 ; 35,1)$ & $12,7(3,9 ; 62,5)$ & $3,9(3,9 ; 66,6)$ & 0,8339 & 0,4833 & 0,5294 \\
\hline IFN-g (pg/ml) & $3,9(3,9 ; 47,5)$ & $3,9(3,9 ; 21,9)$ & $3,9(3,9 ; 34,0)$ & 0,0528 & 0,6726 & 0,0801 \\
\hline TNF-a (pg/ml) & $3,9(3,9 ; 51,6)$ & $10,1(3,9 ; 87,5)$ & $14,1(3,9 ; 85,8)$ & 0,5294 & 0,2050 & 0,7263 \\
\hline CD14s (ng/ml) & $3577(2978 ; 4,208)$ & $3,205(2651 ; 3759)$ & $3,151(2479 ; 3438)$ & 0,0873 & 0,6604 & 0,2093 \\
\hline CD163s (ng/ml) & $246(207 ; 293)$ & $159(113 ; 221)$ & $171(117 ; 192)$ & 0,0029 & 0,6604 & 0,2093 \\
\hline
\end{tabular}

Basal: previo al inicio del tratamiento con ADD

Estadística: los valores se expresan como mediana (rango intercuartil). Los valores de $p$ se calcularon utilizando Wilcoxon test

asociados a células mononucleares de sangre periférica. Se tomaron muestras en distintas etapas del tratamiento para VHC: basal (pre-tratamiento anti-VHC), final del tratamiento y al año post tratamiento. Se estudiaron los mediadores solubles IP-10, TNF-a, IL-6, IL-1 $\beta$ (marcadoras de inflamación sistémica), IL-17 (LT CD4+ Th17), IL-2, IFN-Y (LT CD4+ con perfil Th1), IL-8 (inducción de neutrofilia), CD23s, ICAMs, CD14s, CD163s (marcadores de activación de monocitos/ macrófagos). Observamos que los niveles de IP-10, ICAMs, IL-8, IFN- $\gamma$ y CD23s disminuyeron al final del tratamiento con $A A D$ y se mantuvieron en valores significativamente menores al basal luego del año post tratamiento para VHC. Este fenómeno podría explicarse por la disminución del estímulo generado por VHC sobre la activación del sistema inmune, dando por resultado una menor inflamación sistémica. Por otro lado, ICAMs y CD163s podrían correlacionarse con una mayor activación de la transcripción basal en las células latentemente infectadas por $\mathrm{VIH}$, dado que ambas citoquinas se relacionan directamente con los niveles de ARN sin splicing/ ADN integrado (parámetros asociados a los reservorios virales de VIH). Si bien el tratamiento con AAD permite eliminar el VHC, esto podría también impactar en la dinámica de la infección por VIH. Cabe destacar que ambos marcadores, ICAMs y CD163s, contribuyen en la activación de monocitos y macrófagos, con lo cual los resultados observados indicarían un potencial rol de estos tipos celulares en la dinámica de los reservorios de $\mathrm{VIH}$. No observamos resultados significativos en las distintas etapas del tratamiento con AAD o con los reservorios virales de $\mathrm{VIH}$ para el resto de los marcadores mencionados (33).

\section{Conclusión}

Son varias las hipótesis descriptas sobre la inmunopatogénesis de la coinfección por VIH/VHC. Se plantea la acción directa de ambos virus sobre diversos tejidos, estimulando entre sí su replicación, además de la respuesta inmunológica que producen en el hospedador, exacerbando la misma. Todos ellos son factores que favorecerían la inflamación sistémica, llevando a una progresión acelerada de comorbilidades, particularmente fibrosis hepática, cirrosis y carcinoma hepatocelular. Si bien son varios los mediadores solubles de activación inmunológica, aún no sehan podido definir biomarcadores de progresiónóptimos para el seguimiento de los individuos en coinfectados por $\mathrm{VIH} / \mathrm{VHC}$.

\section{Perspectivas a futuro}

Restan aún comprender varias cuestiones respecto a la dinámica virus-hospedador en las infecciones por VIH y VHC. Adquirir este conocimiento permitiría mejorar los tratamientos respecto no solo a la eliminación de los patógenos sino también a las secuelas que las infecciones provocan. Es bien conocido que índices de inflamación sistémica y coagulación se reconocen como predictores importantes de morbilidad y mortalidad en la infección por VIH controlada por el TARV. Para el caso del VHC, el estudio del perfil de marcadores solubles proinflamatorios, en distintas etapas del tratamiento con AAD, tiene un fuerte potencial como herramienta clínica adicional en la evaluación del estado inflamatorio del individuo y del riesgo de desarrollo de comorbilidades. Esto podría aplicarse tanto en el contexto de monoinfección por VHC como de coinfección por VIH. 


\section{Bibliografía}

1. Comisión de Hepatitis Virales. Sociedad Argentina de Infectología. Manejo de Hepatitis Virales en pacientes VIH. Guías de práctica clínica. 2018.

2. Platt L, Easterbrook P, Gower E, McDonald B., Sabin K., McGowan C., et al. Prevalence and burden of HCV coinfection in people living with HIV: a global systematic review and meta-analysis. Lancet Infect Dis 2016;16(7):797-808.

3. Boletin sobre hepatitis virales en la Argentina $N^{\circ} 1$. Año 1. Octubre 2019. Ministerio de Salud y Desarrollo Social, República Argentina.

4. https://www.who.int/es/news-room/fact-sheets/detail/ hepatitis-c. Fecha de publicación 9 de Julio de 2019. Acceso: 06 de octubre de 2020.

5. Estrategia mundial del sector de salud contra las hepatitis víricas, 2016-2021; Hacia el fin de las hepatitis víricas. Organización Mundial de la Salud. Junio 2016.

6. Clement M., Collins L., Wilder J., Mugavero M., Barker T., Naggie S. Hepatitis C Virus Elimination in the Human Immunodeficiency Virus-Coinfected Population: Leveraging the Existing Human Immunodeficiency Virus Infrastructure. Infect Dis Clin North Am. 2018; 32(2): 407423.

7. Sato H., Adachi E., Lim L., Koga M., Koibuchi T., Tsutsumi T., et al. CD4/CD8 ratio predicts the cellular immune response to acute hepatitis $\mathrm{C}$ in HIV-coinfected adults. J Infect Chemother 2019; 25: 646-648.

8. Salido J., Ruiz M., Trifone C., Figueroa M., Caruso M., Gherardi M., et al. Phenotype, Polyfunctionality, and Antiviral Activity of in vitro Stimulated CD8+ T-Cells from HIV+ Subjects Who Initiated cART at Different Time-Points After Acute Infection. Front. Immunol. 2018; 9:2443.

9. Sehgal M., Khan Z., Talal A., Jain P. Dendritic Cells in HIV-1 and HCV Infection: Can They Help Win the Battle? Virology: Research and Treatment. 2013; 4: 1-25.

10. Liberto M., Zicca E., Pavia G., Quirino a., Marascio N., Torti C., et al. Virological Mechanisms in the Coinfection between HIV and HCV. Mediators of Inflammation. 2015; Article ID 320532: 1-7.

11. Wu X., Ishaq M., Hu J., Guo D. HCV NS3/4A protein activates HIV-1 transcription from its long terminal repeat. Virus Research. 2008; 135 (1): 155-160.

12. Danta M., Semmo N., Fabris P., Brown D., Pybus O., Sabin C., et al. Impact of HIV on Host-Virus Interactions during Early Hepatitis C Virus Infection. J Infect Dis. 2008; 197: 1558-1566.

13. Mastroianni C., Lichtner M., Mascia C., Zuccala P., Vullo V. Molecular mechanisms of liver fibrosis in HIV/HCV coinfection. Int J Mol Sci. 2014; 15(6): 9184-9208.

14. Munshi N., Balasubramanian A., Koziel M., Ganju R., Groopmanb J. Hepatitis C and Human Immunodeficiency Virus Envelope Proteins Cooperatively Induce Hepatocytic Apoptosis via an Innocent Bystander Mechanism. J Infect Dis. 2003. 188: 1192-1204.

15. Mascia .C, Lichtnera M., Zuccalà P., Vita S., Tieghi T., Maroccoa R., et al. Active HCV infection is associated with increased circulating levels of interferon-gamma (IFN-y)-inducible protein-10 (IP-10), soluble CD163 and inflammatory monocytes regardless of liver fibrosis and HIV coinfection. Clinics and Research in Hepatology and Gastroenterology 2017; 41: 644-655.

16. Lidofsky A., Holmes J., Feeney E., Kruger A., Salloum S., Zheng $H_{\text {., }}$ et al. Macrophage Activation Marker Soluble CD163 Is a Dynamic Marker of Liver Fibrogenesis in Human Immunodeficiency Virus/Hepatitis C Virus Coinfection. J Infect Dis. 2018; 218: 1394-1403.

17. Tudesq J-J, Dunyach-Remy C, Combescure C, Doncesco R, Laureillard D, Lavigne J-P, et al. Microbial translocation is correlated with HIV evolution in HIV-HCV coinfected patients. PLoS ONE. 2017; 12 (9): e0183372.

18. Márquez M., Fernández Gutiérrez del Álamo C., GirónGonzález J. Gut epithelial barrier dysfunction in human immunodeficiency virus-hepatitis $\mathrm{C}$ virus coinfected patients: Influence on innate and acquired immunity. World J Gastroenterol. 2016; 22(4): 1433-1448.

19. Hunt P., Sinclair E., Rodriguez B., SVIHe C., Clagett B., Funderburg N., et al. Gut epithelial barrier dysfunction and innate immune activation predict mortality in treated HIV infection. J Infect Dis. 2014; 210 (8):1228-1238.

20. Shmagel K., Saidakova E., Korolevskaya L., Shmagel N., Chereshnev V., Anthony D., et al. Influence of hepatitis C virus coinfection on CD4+ T cells of HIV-infected patients receiving HAART. AIDS. 2014; 28:2381-2388.

21. Medrano L., Garcia-Broncanoa P., Berenguer J., González García J., Jiménez Sousaa M., Guardiolaf J. et al. Elevated liver stiffness is linked to increased biomarkers of inflammation and immune activation in HIV/hepatitis C virus-coinfected patients. AIDS 2018; 32 (9): 1095-1105.

22. Shmagel K., Saidokova E., Shmagel G., Korolevskaya L., Chereshnev V., Robinson J., et al. Systemic inflammation and liver damage in HIV/HCV co-infection. VIH Med. 2016; 17 (8): 581-589.

23. Keating S., Dodge J., Norris P., Heitman J., Gange S., French A., et al. The effect of HIV infection and HCV viremia on inflammatory mediators and hepatic injury-The Women's Interagency VIH Study. PLoS ONE. 2017; 12 (9): e0181004.

24. Garcia-Broncano P., Medrano L., Berenguer J., GonzálezGarcía J., Jiménez-Sousa M., Carrero A., et al. Dysregulation 
of the Immune System in HIV/HCV-Coinfected Patients According to Liver Stiffness Status. Cells. 2018; 7, 196: 1-16.

25. Miedema F. Immunological abnormalities in the natural history of HIV infection: mechanisms and clinical relevance. Immunodefic Rev. 1992; 3 (3):173-93.

26. Del Campo J., Gallego P., Grande L. Role of inflammatory response in liver diseases: Therapeutic strategies. World $\mathrm{J}$ Hepatol. 2018; 10(1): 1-7.

27. Kanwar B., Favre D., McCunea J. Th17 and regulatory T cells: implications for AIDS pathogenesis. Curr Opin HIV AIDS. 2010; 5(2): 151-157.

28. Parisi S., Andreis S., Mengoli C., Menegotto N., Cavinato S., Scaggiante R., et al. Soluble CD163 and soluble CD14 plasma levels but not cellular HIV DNA decrease during successful interferon-free anti-HCV therapy in HIV-1$\mathrm{HCV}$ co-infected patients on effective combined anti-VIH treatment. Med Microbiol Immunol. 2018; 207: 183.

29. Kostadinova L., SHIV C., Judge C., Zebrowski E., Compan A., Rife K., et al. During hepatitis $\mathrm{C}$ virus ( $\mathrm{HCV}$ ) infection and HCV-HIV coinfection, an elevated plasma level of autotaxin is associated with lysophosphatidic acid and markers of immune activation that normalize during interferon-free HCV Therapy. J Infect Dis. 2016; 214: 1438-1448.

30. Mascia C., Vita S., Zuccalà P., Marocco R., Tieghi T., Savinelli S., et al. Changes in inflammatory biomarkers in HCV-infected patients undergoing direct acting antiviralcontaining regimens with or without interferon. PLoS One. 2017; 12: e0179400.

31. Knudsen T., Ertner G., Petersen J., Møller H., Moestrup S., Eugen-Olsen J., et al. Plasma soluble CD163 level independently predicts all-cause mortality in HIV-1-infected individuals. J Infect Dis. 2016; 214: 1198-1204.

32. Sandler N., Wand H., Roque A., Law M., Nason M., Nixon D., et al. Plasma levels of soluble CD14 independently predict mortality in HIV infection. J Infect Dis. 2011; 203: 780-790.

33. Ghiglione Y., Polo M., Urioste A., Rhodes A., Czernikier A., Trifone C. Hepatitis C Virus (HCV) Clearance After Treatment With Direct-Acting Antivirals in Human Immunodeficienc Virus (HIV)-HCV Coinfection Modulates Systemic Immune Activation and HIV Transcription on Antiretroviral Therapy. OFID. 2020;7(5):ofaa115.
Systemic inflammation and immune dysregulation: role in the pathogenesis of HIV / HCV coinfection

The immune dysfunction associated with Human Immunodeficiency Virus (HIV) infection is generated by a chronic stimulation of the immune system, because of the inability to eradicate the virus from the host. This immune dysfunction is exacerbated in the context of coinfection with Hepatitis C Virus (HCV). Systemic inflammation caused by coinfection with both viruses generates an increase in morbidity and mortality in affected individuals. There are several soluble mediators of immunological activation, such as IP-10, TNF-a, IL-6, IL-1 $\beta$ (systemic inflammation markers); IL-17 (CD4+ T cells Th17); IL-2, IFN-y (CD4+ T cells Th1); IL-8 (neutrophilia); CD23s, ICAMs, CD14s, CD163s, lipopolysaccharide (LPS) (monocyte/macrophage activation markers and bacterial translocation); among others. Currently, more studies are needed to define optimal progression biomarkers for the follow-up of HIV/HCV coinfected individuals. In this review, we focus on the immunopathological mechanisms of HIV/ $\mathrm{HCV}$ infection involved in inflammation, liver damage and its impact on the morbidity and mortality of affected individuals.

Key words: HIV, HCV, immune dysfunction, immune dysregulation, inflammation. 